\title{
Dürr, Christian (2017). Memorias incómodas. El dispositivo de la desaparicion y el testimonio de los sobrevivientes de los Centros Clandestinos de Detención, Tortura y Exterminio. Temperley: Tren en Movimiento, $224 \mathrm{pp}$.
}

\section{Iván Wrobel}

Universidad de Buenos Aires, Argentina

ivanwrobel@gmail.com

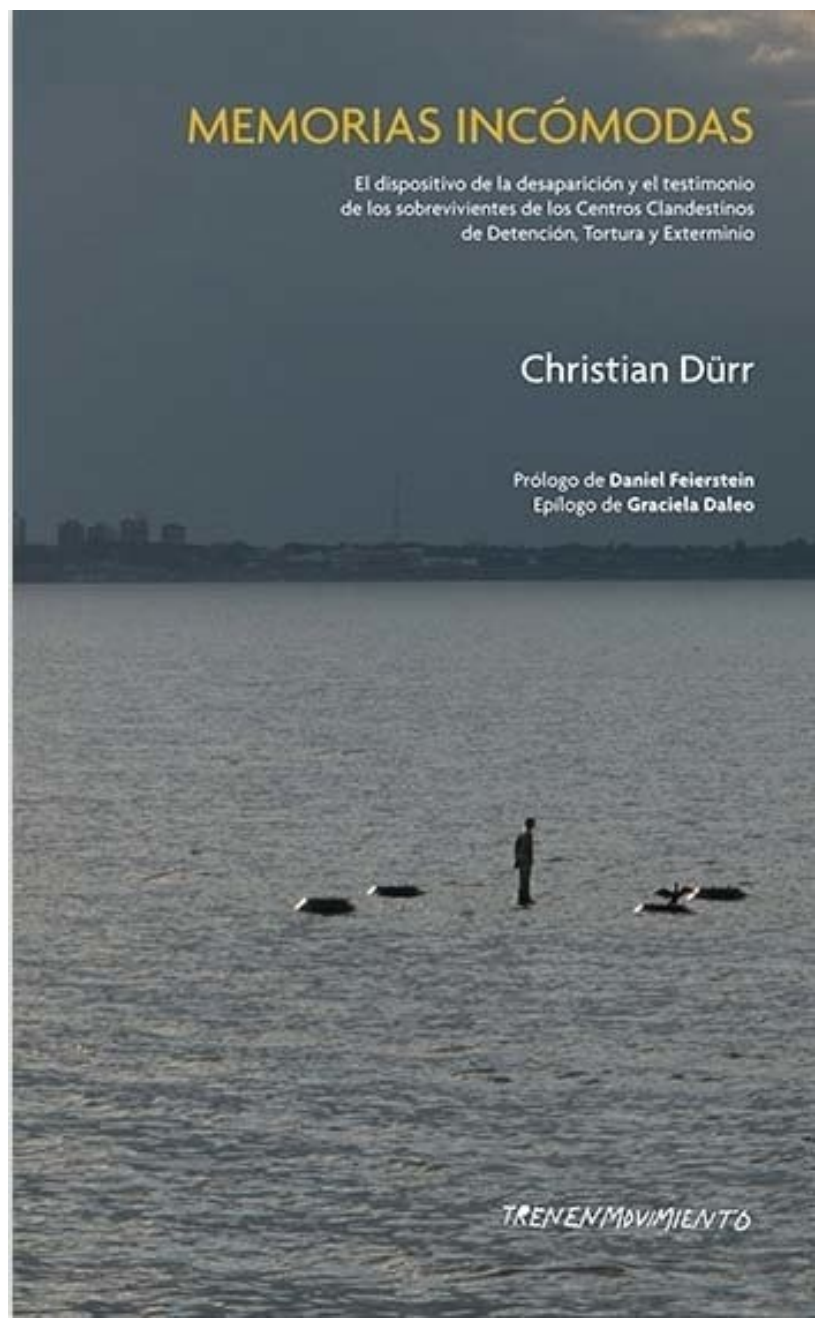

Christian Dürr es un filósofo e historiador austríaco especialista en la experiencia concentracionaria nazi. En el marco de una estancia de posdoctorado en nuestro país, estudió el funcionamiento de los Centros Clandestinos de Detención, Tortura y Exterminio (CCDTyE) con el objetivo de hacer un estudio comparativo entre ambos casos. El resultado, el libro aquí reseñado, tiene la particularidad de ser dos libros en uno. Por un lado, se trata de un estudio exhaustivo sobre el funcionamiento de los CCDTyE y su rol dentro 
del dispositivo de control establecido por la última dictadura cívico militar. Por el otro, y este es el aspecto más interesante del libro, se trata de una especie de relato coral acerca de la experiencia de la desaparición narrado por sus propios protagonistas y que abarca desde la vida previa al secuestro hasta tiempo después de la liberación.

En efecto, estos testimonios, calificados por el autor como "memorias incómodas" (lo que da nombre al libro), son presentados a lo largo de todo trabajo de forma textual, intercalados con breves comentarios en los que Dürr los amplía y los contextualiza. Como dice el autor, "cada una de esas voces por sí habla de una experiencia personal y aislada; pero todos en su conjunto hablan de una experiencia en común" (Dürr, 2017, p. 24). Esta estrategia nos pone, de una forma muy gráfica, frente a una verdad, valga la redundancia, incómoda: la literatura académica no les ha dado suficiente lugar a las voces de las y los sobrevivientes. Es por eso que en los capítulos centrales del libro el lugar principal lo ocupan estos testimonios de quienes estuvieron desaparecidos y hoy pueden contarlo.

El primer capítulo constituye, junto con el último, el apartado más teórico del libro. En este capítulo Dürr inscribe su trabajo en la tradición inaugurada por el filósofo francés Michel Foucault e identifica a los CCDTyE como parte de un dispositivo de poder establecido por la dictadura cívico militar. A su vez, retoma al sociólogo alemán Wolfang Sofsky, quien también se inspiró en la obra de Foucault para estudiar los campos de concentración nacionalsocialistas. En este capítulo Dürr introduce también su principal referencia para estudiar el caso argentino: el trabajo Poder y desaparición de Pilar Calveiro, politóloga argentina y sobreviviente de varios CCDTyE. El trabajo histórico y sociológico se verá complementado por las perspectivas de Gabriele Rosethal y Paul Ricoeur, quienes constituyen el principal corpus teórico para el abordaje de los testimonios presentados. Hacia el final del capítulo el autor hace una aclaración importante: los testimonios en los que basa su trabajo son fundamentalmente de sobrevivientes que pasaron por la Escuela de Mecánica de la Armada, por el circuito Atlético-Banco-Olimpo y por La Perla. Sin embargo, Dürr entiende que hay un patrón estructural que es posible hacer extensivo al resto de los CCDTyE del país.

En el segundo capítulo el autor hace un breve trabajo comparativo entre las principales características de los CCDTyE argentinos y los campos de concentración nacionalsocialistas. Dürr señala que los campos de concentración funcionaban bajo una apariencia de legalidad y fueron constituidos de forma visible, como un modo de transmitir amedrentamiento e incertidumbre, pero también como parte del orgullo nacional alemán. Su funcionamiento no sólo no disminuyó con el correr de los años, sino que a medida que el régimen nacionalsocialista se debilitaba los campos de concentración se fortalecían a través de una radicalización de la persecución a quienes no encajaran en la comunidad racial homogénea y purificada. Los CCDTyE, en cambio, y como su nombre lo indica, siempre funcionaron en la más absoluta clandestinidad. Se presentaban ante la sociedad, nos dice el autor, como un "espacio en blanco": no eran mencionados en el discurso oficial ni había un término para nombrarlos. Esta aparente ausencia era parte de una estrategia dictatorial, orientada a difundir el terror desde este espacio aparentemente vacío. Hacia finales de la dictadura los mismos dejaban de funcionar debido a que ya habían cumplido su objetivo, el de desaparecer a parte de la militancia social y política y transformar al resto de la sociedad por medio del terror.

Los capítulos tercero y cuarto constituyen una breve descripción de las entrevistas y los CCDTyE analizados. Aquí hay un gran acierto del autor, que es el de utilizar parte del enorme acervo archivístico de nuestro país para realizar su investigación en vez de partir únicamente de entrevistas propias. La principal fuente de consulta está constituida por la colección del Centro de Estudios sobre Genocidio de la Universidad Nacional de Tres de Febrero. En segundo lugar, el autor recurrió al fondo documental de Memoria Abierta. Estos fondos institucionales fueron complementados por entrevistas propias que tenían el objetivo de contrastar la información presente en los fondos antes mencionados. Es interesante que el mismo autor admite que las interpretaciones y las narrativas a grandes rasgos se repiten cuando se comparan entrevistas realizadas a la misma persona. Por último, una cuarta fuente de consulta fueron las declaraciones realizadas en el Juicio a las Juntas. Una reflexión importante que aporta Christian Dürr es la de un problema que, 
él mismo nos dice, su trabajo no logra resolver: la mayoría de los testimonios presentes en archivos son de sobrevivientes que continuaron militando después de su liberación; la voz de aquellas y aquellos que no lo hicieron permanece excluida de la mayoría de los trabajos académicos.

En el quinto capítulo comienza el centro del trabajo de Dürr. Aquí se analiza la vida de las y los sobrevivientes antes de su secuestro, marcada por la clandestinidad y la constante persecución. Como se ve, la marginación, la estigmatización, la exclusión de la sociedad antecedían y comenzaban mucho antes de la desaparición. La necesidad de vivir escondiéndose, sin un domicilio o un trabajo fijos y siguiendo estrictas normas de seguridad impedían, o por lo menos dificultaban, una inserción social de cualquier tipo. Las organizaciones políticas se cerraban y el contacto entre la militancia se reducía al mínimo indispensable. Incluso los vínculos familiares se veían alterados, tanto por la estigmatización que sufrían quienes eran perseguidos/as como por las amenazas que sufrían sus familias.

El sexto capítulo está dedicado a lo que el autor denomina el "período intenso". Este momento ocurría inmediatamente después de la desaparición y estaba signado por un sometimiento intensivo de las y los secuestrados a la tortura. Esto tenía, sobre todo, un fin estratégico, ya que los torturadores sabían que las primeras horas y días eran claves para obtener información. Para el autor parte central de este primer momento era el desconcierto. La tortura física podía ocurrir en cualquier momento, incluso fuera de los espacios preparados para ese fin; los ruidos, el aislamiento, la oscuridad, la nueva cotidianeidad constituían parte de una tortura psicológica que tenía como objetivo el quiebre de las y los desaparecidos como seres humanos.

En el séptimo capítulo el autor aborda lo que denomina la "normalización”. Este período está marcado por una disminución importante de la violencia física. A partir de ahora la tortura será sobre todo psicológica. Largas horas de silencio y oscuridad, mínimo contacto social, incertidumbre, todo esto era parte del plan de la dictadura para modelar a las y los desaparecidos. A partir de este momento, también como parte de un plan calculado, comienza incluso a relajarse el control. Quienes están en esta etapa reciben permisos para circular, se alivia la obligación de usar la capucha, algunas y algunos incluso son convocados a trabajar dentro del CCDTyE. También en este momento es cuando con más claridad pueden verse las estrategias de resistencia, orientadas sobre todo a sobrevivir, pero también a ayudar a otras y otros detenidos. Dürr rescata el ejemplo de un detenido a quien se le había encargado reparar la picana eléctrica y, pese a que no podía negarse, decidió alterarla para que diera descargas más leves. El objetivo de esta "normalización" era que las y los detenidos se reconstituyeran como sujetos; sin embargo, no se buscaba que volvieran a ser quienes eran sino que internalizaran las fronteras del CCDTyE. Dürr resalta un fragmento de una entrevista realizada a Graciela Daleo: "Hubo un intento de desestructuración de nosotros como individuos y como colectivos. De desarmarte como si fueras un rompecabezas y después de volver a armarte. Pero ellos se quedaron con una pieza" (Dürr, 2017, p. 95).

En el octavo capítulo el autor analiza el momento de la "reaparición”. Nuevamente, la liberación de las y los detenidos era parte de un cálculo del poder dictatorial. Su objetivo era que las y los sobrevivientes difundieran el terror a través de sus relatos de lo que habían vivido. Dürr identifica que en todos los casos esta "liberación" fue gradual. Ya sea que estuviera antecedida por salidas transitorias, por breves contactos con la familia o que estuviera marcada por llamados y visitas inesperadas de los grupos de tareas, los secuestradores siempre se encargaban de hacer saber que "seguían presentes" . También identifica cierta actitud "paternalista", parte del cálculo de los represores. Quienes antes habían sido los más cruentos torturadores ahora intentaban mostrarse benevolentes e incluso amigables.

El noveno capítulo es, probablemente, el mayor aporte de Dürr, ya que analiza un aspecto que aún no ha sido del todo explorado: la reinserción de las y los sobrevivientes. A las secuelas de la tortura se suma una dificultad para reinsertarse en la sociedad que aparece en la totalidad de los relatos analizados. La mayoría no podía encontrar lugares o interlocutores para contar lo que habían vivido. También cargaban con una doble estigmatización; si en un primer momento se decía que "por algo será" que desaparecieron, ahora la acusación 
plantea que "por algo será" que sobrevivieron. Esta doble sospecha, que Dürr entiende que socialmente ayudaba a racionalizar el terror, prolongaba el aislamiento de quienes habían salido con vida de los CCDTyE. El primer espacio de habla y escucha fue constituido entre sobrevivientes. Allí todas y todos necesitaban narrar sus vivencias pero también escuchar lo que habían vivido otros compañeros y compañeras. Era, según Dürr, una forma de socializar los traumas individuales. El autor interpreta que la elaboración personal de las y los sobrevivientes fue central para la elaboración colectiva de la sociedad argentina. Más adelante en el tiempo, los juicios realizados a partir del 2003 colaboraron para brindarles un espacio de protagonismo. La mayoría de las y los sobrevivientes resalta, según Dürr, la importancia de dar su testimonio.

El décimo y último capítulo constituye una elaboración teórica a partir de lo estudiado a lo largo de todo el trabajo. Siguiendo a Gilles Deleuze, Dürr define al CCDTyE como un espacio de control permanente dentro de un dispositivo de control. El CCDTyE, a diferencia del campo de concentración nacionalsocialista, debe ser siempre invisible. No hay un espacio concreto, no hay cuerpos concretos, solo un vacío discursivo. Cuando la hegemonía es nuevamente reestablecida, cuando el poder percibe que logró moldear nuevamente la sociedad, los CCDTyE dejan de tener sentido y comienzan gradualmente a dejar de funcionar. Sin embargo, Dürr reconoce que este proceso será siempre incompleto y que la existencia de los testimonios aquí analizados son la prueba viviente de ello. Para él, las y los sobrevivientes "son el ejemplo vivo de que aun en las circunstancias más adversas la emancipación y la autonomía siguen estando como posibilidades en el horizonte" (Dürr, 2017, p. 202). 